\title{
Simultaneous Estimation and Validation of Atorvastatin Calcium and Aspirin in Combined Capsule Dosage Form by RP HPLC Method
}

\author{
B. V. SUMA*,K. KANNAN ${ }^{1}$, V. MADHAVAN ${ }^{2}$, CHANDINI R. NAYAR $^{3}$
}

* Research scholar, SASTRA University, Thanjavur-613402, Tamil Nadu, India, Department of Pharmaceutical Chemistry, M.S.Ramaiah College of Pharmacy, Bangalore 560054, Karnataka India.

1. Department of pharmacy, Annamalai University, Annamalai Nagar-608002, Chidambaram, Tamil Nadu, India.

2. Department of Pharmacognosy, M.S.Ramaiah College of Pharmacy, Bangalore - 560054, Karnataka India.

3. School of Chemical and Biotechnology, SASTRA University, Thanjavur-613402, Tamil

Nadu, India.

bvs332@gmail.com

bvs332@yahoo.co.in

Received 24 October 2011; Accepted 30 December 2011

\begin{abstract}
A new simple, specific, precise and accurate revere phase liquid chromatography method has been developed for estimation of atorvastatin calcium (AST) and ASPIRIN (ASP) simultaneously in a combined capsule dosage forms. The chromatographic separation was achieved on a 5 - micron C 18 column (250x 4.6mm) using a mobile phase consisting of a mixture of Acetonitrile: Ammonium Acetate buffer $0.02 \mathrm{M}(68: 32) \mathrm{pH}$ 4.5. The flow rate was maintained at $0.8 \mathrm{ml} / \mathrm{min}$. The detection of the constituents was done using UV detector at $245 \mathrm{~nm}$ for AST and ASP. The retention time of AST and ASP were found be $4.5915 \pm 0.0031 \mathrm{~min}$ and $3.282 \pm 0.0024$ min respectively. The developed method was validated for accuracy, linearity, precision, limit of detection (LOD) and limit of quantification (LOQ) and robustness as per the ICH guidelines.
\end{abstract}

Key words: Simultaneous estimation, Atorvastatin calcium, Aspirin, Capsule form and RP HPLC.

\section{Introduction}

Atorvastatin calcium is chemically a calcium salt of ( $\beta$ R, 8 R)-2-(4 - fluoro-phenyl $)-\alpha, \delta$ di hydroxyl 5(1 methyl ethyl) 1, 3, phenyl, 4 (phenyl amino) carbonyl) $-1 \mathrm{H}$ pyrroleheptanoic acid tri hydrate used as antihyperlipidaemic. It is official in Indian pharmacopoeia 
${ }^{1}$ Aspirin is chemically 2-(Acetyloxy) benzoic acid, best known as anti-platelet drug. It is official both in I.P and B.P. ${ }^{2}$

Detailed survey of literature for atorvastatin calcium (AST) revealed several methods based on different techniques like extractive Spectrophotometry ${ }^{3}$, HPLC ${ }^{4-8}$, HPLC ${ }^{\text {9-11 }}$ for its determination in human serum, capillary electrophoresis ${ }^{12}$, HPTLC for its determination in pharmaceutical. ${ }^{13}$

Similarly literature survey for aspirin reveals several methods based on Spectrophotometry ${ }^{14}$, Raman spectroscopy ${ }^{15}$ RP- HPLC ${ }^{16}$. This paper describes a simple, precise and accurate RP HPLC method for the estimation of AST and ASP combination in a capsule dosage form.

\section{Material and methods}

Chemical and reagents

AST was the generous gifts from Biocon Limited Bangalore, and aspirin was procured from Qualigens Fine Chemicals (Glaxo Ltd). Combination of these drugs was purchased from the local market (Ecosprin AV 75 containing Atorvastatin calcium $10 \mathrm{mg}$ and aspirin $75 \mathrm{mg}$ as per the label claim, marketed by USV limited, India). HPLC grade Acetonitrile, ammonia, glacial acetic acid was procured from Merck.

\section{RP HPLC instrumentation and chromatographic conditions}

The following chromatographic conditions were established for the separation of drug and maintained the same parameter throughout the method.

$\begin{array}{ll}\text { System } & \text { High performance liquid chromatograph10AT } \\ & \text { SHIMADZU-SPD10A detector } \\ \text { Column } & \text { SS Grace- C18, 250X } 4.6 \mathrm{~mm}, 5 \mu \mathrm{m} \\ \text { Detector } & \text { UV detector } \\ \text { Mobile phase } & \text { Acetonitrile: Ammonium acetate 0.02M (68:32) pH 4.5. } \\ \text { Detection wavelength } & 245 \mathrm{~nm} \\ \text { Mode } & \text { Isocratic } \\ \text { Sample Size } & 20 \mu 1 \\ \text { Temperature } & \text { Room temperature }\end{array}$

Preparation of standard stock solution

a) Preparation of standard stock solution of AST: An accurately weighed quantity equivalent to $10 \mathrm{mg}$ AST was dissolved in $25 \mathrm{ml}$ of methanol and then the volume was made up to $50 \mathrm{ml}$ with same solvent.

b) Preparation of standard stock solution of AST: An accurately weighed quantity equivalent to $75 \mathrm{mg}$ ASP was dissolved in $25 \mathrm{ml}$ of methanol and then the volume was made up to $50 \mathrm{ml}$ with same solvent.

c)

\section{Validation of the $\operatorname{method}^{17}$}

The method was validated as per ICH guide line. The parameters checked were linearity, accuracy, precision, limit of detection, limit of quantification, robustness and specificity.

\section{System suitability testing}

A standard solution was prepared using AST and NA working standard as per the test method and was injected nine times into the HPLC system. The parameters like theoretical plates, tailing factor and resolution for the standard solution were calculated. 


\section{Calibration curve}

From the working standard solution of AST $(200 \mu \mathrm{g} / \mathrm{ml})$ and AST $(1500 \mu \mathrm{g} / \mathrm{ml})$, appropriate aliquots of AST and ASP stock solution were diluted in methanol to obtain final stock solution of 2, 4, 6, $810 \mu \mathrm{g} / \mathrm{ml}$ of AST and 15,30,45, 60, $75 \mu \mathrm{g} / \mathrm{ml}$ of ASP. The solutions were injected using a $20 \mu$ lixed loop system and chromatograms were recorded. Calibration curve were constructed and regression equation were computed for AST and AST.

\section{Specificity}

A blank solution (mobile phase) was injected and the chromatogram showed no inferring peaks at retention time of the two drugs. The chromatogram of AST and ASP extracted from the tablet dosage form were compared with those acquired from AST and ASP standards, correlation was good (in terms of retention time and area) indicates specificity of method.

\section{Precision: (Reproducibility)}

The precision of the method was verified by performing the intraday and interday precision. The intraday and interday precision of the proposed method was determined by estimating the corresponding response three times on the same day and on three different days.

\section{Accuracy: (\% Recovery)}

For accuracy of method, recovery studies were carried out by applying a known amount of standard AST and ASP at a level of 80,100,120 \% to the sample solution (standard addition method). Three determinations were performed at each level, using same chromatographic condition as describe above.

\section{Limit of Detection (LOD) and Limit of quantification (LOQ):}

The LOD and LOQ were calculated using following equations as per International conference on Harmonization guide line

$\mathrm{LOD}=3.3 \times \sigma / \mathrm{S}$

$\mathrm{LOQ}=10 \times \sigma / \mathrm{S}$

Where $\sigma$ is standard deviation of the response and $\mathrm{S}$ is the standard deviation of $\mathrm{y}$ intercept of regression lines.

\section{Robustness}

Robustness was checked by making a slight deliberate change in the experimental procedure like slight change in the temperature, flow rate and $\mathrm{pH}$ and the data are expressed in terms of relative standard deviation.

\section{Analysis of the marketed products}

To find the content of the marketed formulation, (Ecosprin AV 75 containing Atorvastatin calcium $10 \mathrm{mg}$ and aspirin $75 \mathrm{mg}$ as per the label claim, marketed by USV limited, India), twenty tablets were weighed and average weight was determined, powdered, from this equivalent weight of $10 \mathrm{mg}$ for AST and $75 \mathrm{mg}$ of ASP was transferred into a $50 \mathrm{ml}$ volumetric flask, containing $15 \mathrm{ml}$ of methanol and sonicated for 30 minutes, filtered through Whatmann filter paper No.41and then volume was made up to $50 \mathrm{ml}$ with methanol.

\section{Results and Discussion}

\section{Validation}

To optimize the HPLC parameters, several mobile phases were tried and satisfactory results were obtained by using the mobile phase consisting of Acetonitrile: ammonium acetate 
$0.02 \mathrm{M}(68: 32)$ at of $\mathrm{P}^{\mathrm{H}}$ of 4.5 , with a flow rate of $0.8 \mathrm{ml} / \mathrm{min} . \mathrm{UV}$ detection was carried out at $245 \mathrm{~nm}$ and run time was $15 \mathrm{~min}$. The selection of the mobile phase was made on the basis of resolution, asymmetric factor, and theoretical plates. The retention time of AST and ASP was found to $4.5915 \pm 0.0031 \mathrm{~min}$ and $3.282 \pm 0.0024 \mathrm{~min}$ respectively. A typical chromatogram of the test is shown in Figure 1.

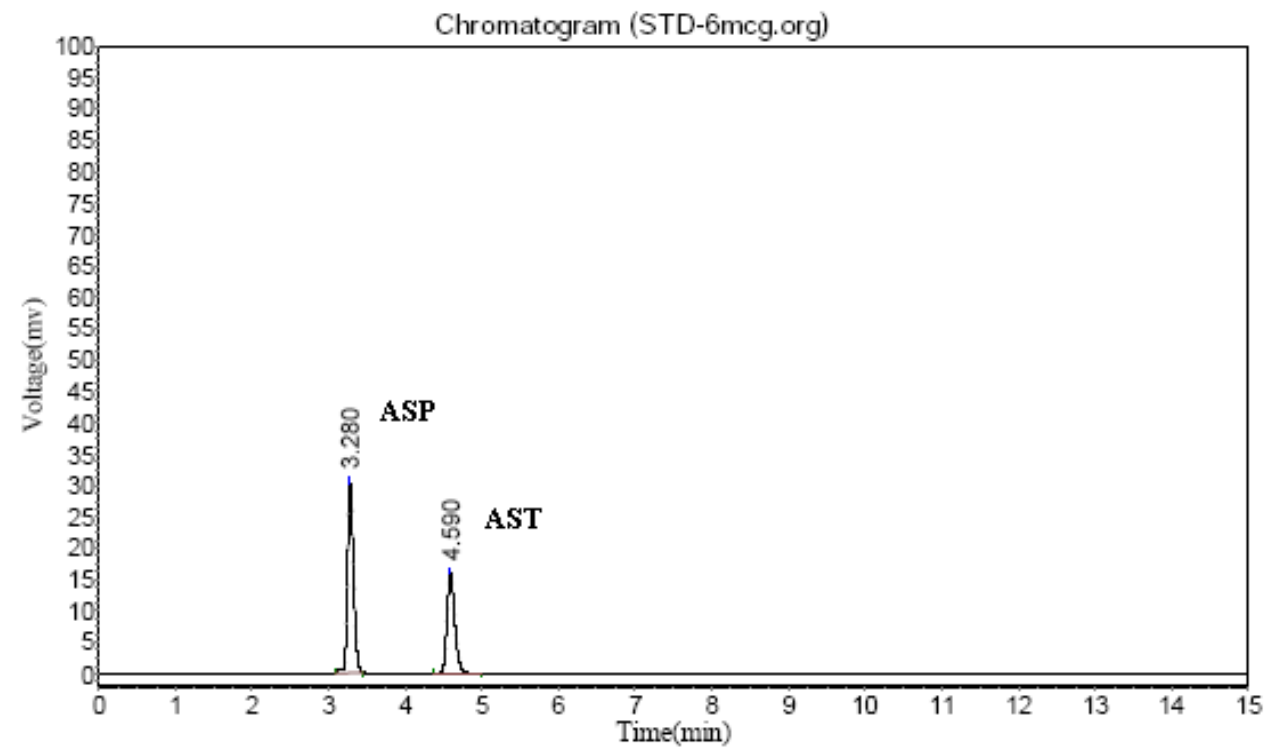

Figure 1. A Representative Chromatogram of Atorvastatin Calcium (AST) and Aspirin (ASP) at $245 \mathrm{~nm}$.

\section{System suitability parameters}

System suitability parameters proved that the proposed method suits for the simultaneous estimation of AST and ASP. After various trials performed, chromatogram for AST and ASP was found satisfactory on, using mobile phase composition of Acetonitrile: Ammonium acetate $0.02 \mathrm{M}(68: 32) \mathrm{pH}$ 4.5.Drug peak was found to be symmetrical as observed from asymmetry factor of 1.4315 for AST and 1.4455 for ASP. Resolution of the proposed method was found to be satisfactory and the results are given in table 1 .

Table: 1. Study of System Suitability Parameters.

\begin{tabular}{llll}
\hline Sl.No. & Parameters & AST & ASP \\
\hline 1 & $\begin{array}{l}\text { AUC(Area under } \\
\text { curve) }{ }^{*} \\
\pm \text { S.D }\end{array}$ & 112515.9401 & 165139.9916 \\
& \% RSD & 277.8376 & 848.5548 \\
& Resolution & 0.058 & 0.513 \\
2 & 4.4400 & 0.7935 \\
3 & Theoretical levels & 9865.4064 & 8070.8288 \\
4 & Tailing factor & 1.2601 & 1.2557 \\
5 & Asymmetry & 1.4315 & 1.4455 \\
\hline
\end{tabular}

\footnotetext{
* Mean of nine trials.
} 


\section{Linearity}

The linear regression data revealed a good linear relationship over the concentration range of $2-10 \mu \mathrm{g} / \mathrm{ml}$ for AST and $15-75 \mu \mathrm{g} / \mathrm{ml}$ for ASP with correlation coefficient $\left(\mathrm{r}^{2}=0.9998\right)$ for AST and correlation coefficient $\left(\mathrm{r}^{2}=0.9994\right)$ for ASP respectively. The results are showed in table 2 and Figure 2 and Figure 3.

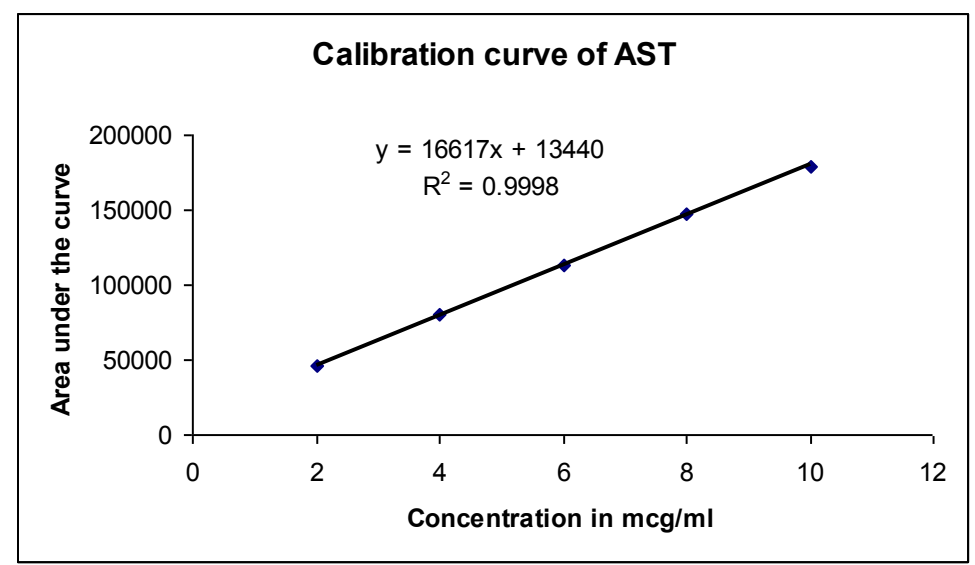

Mean of six trials

Figure 2. Linearity graph of Atorvastatin calcium (AST).

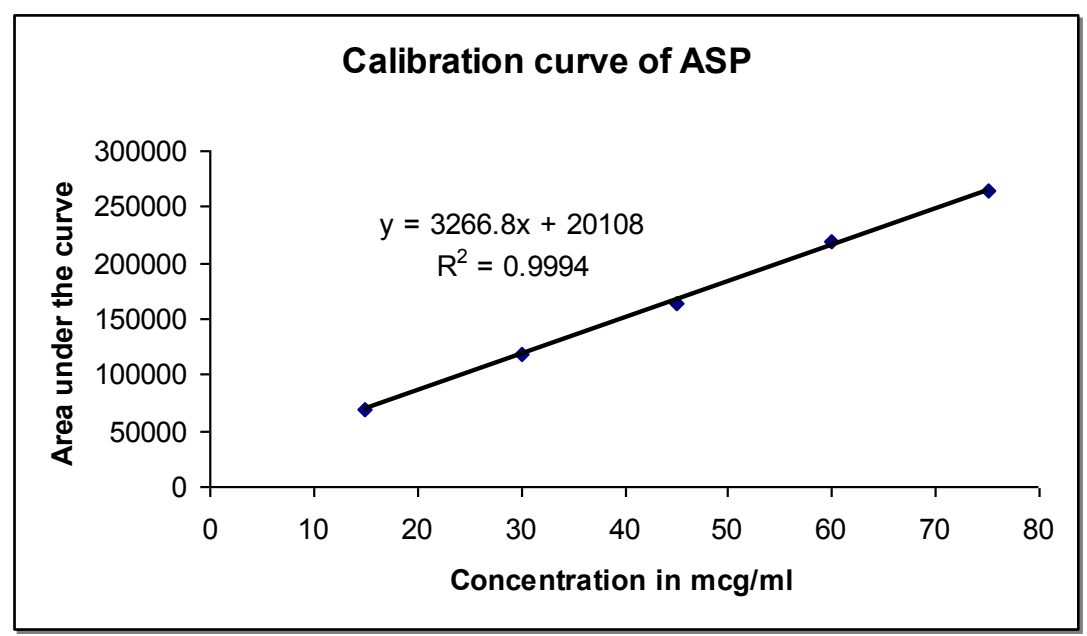

Mean of six trials

Figure 3. Linearity graph of Aspirin (ASP).

\section{Specificity}

The method was found to be specific since no interferences chromatograms were seen when carried out in presence of additives, when only mobile phase was injected. 
Table 2. Linear regression data of AST and NA.

\begin{tabular}{llll}
\hline S1.No & Parameters & AST & ASP \\
\hline 1 & Detection Wavelength & $254 \mathrm{~nm}$ & $254 \mathrm{~nm}$ \\
2 & Linearity Range $\mu \mathrm{g} / \mathrm{ml}$ & $2-10$ & $15-75$ \\
3 & Correlation Coefficient( 2$)$ & 0.9998 & 0.9994 \\
4 & $\begin{array}{l}\text { Linearity Regression equation } \\
(\mathrm{y}=\mathrm{mx}+\mathrm{c})\end{array}$ & $\mathrm{Y}=16617 \mathrm{x}+13440$ & $\mathrm{Y}=3266.8 \mathrm{x}+20108$ \\
& LOD & $0.088 \mathrm{ng} / \mathrm{ml}$ & $1.31 \mathrm{ng} / \mathrm{ml}$ \\
5. & LOQ & $0.266 \mathrm{ng} / \mathrm{ml}$ & $3.98 \mathrm{ng} / \mathrm{ml}$ \\
6 & & & \\
7. & Precision(\%RSD) & 0.37 & 0.54 \\
& Intraday & 0.45 & 0.975 \\
& Interday & &
\end{tabular}

\section{Precision}

The proposed method was found to be precise as indicated by percent RSD not more than $2 \%$ as per ICH guidelines for interday and intra day determination. The results are shown in the table 2.

\section{Accuracy}

The proposed method when used for the estimation of AST and ASP from pharmaceutical dosage form after spiking with the standard, afforded recovery of $100.40(80 \%), 99.23 \%$ ( $100 \%), 100.61 \%(120 \%)$ at different levels were found for AST and $99.82 \%(80 \%)$, $100.23 \%$ (100\%), $99.14 \%$ ( 120\%) for ASP respectively, as shown in table 3 and table 4 .

Table 3. Recovery studies of Atorvastatin Calcium Excepted concentration.

\begin{tabular}{llll}
\hline & Level of recovery & & \\
& $80 \%$ & $100 \%$ & $120 \%$ \\
& $8 \mu \mathrm{g} / \mathrm{ml}$ & $10 \mu \mathrm{g} / \mathrm{ml}$ & $12 \mu \mathrm{g} / \mathrm{ml}$ \\
Peak Area* & 90248.359 & 111541.049 & 135718.00 \\
\%RSD & 0.07918 & 0.3414 & 0.06588 \\
Mean \% recovery & 100.40 & 99.23 & 100.61 \\
\hline
\end{tabular}

* Mean of three trials.

Table 4. Recovery studies of Aspirin Excepted concentration.

\begin{tabular}{llll}
\hline & Level of recovery & & \\
& $80 \%$ & $100 \%$ & $120 \%$ \\
& $60 \mu \mathrm{g} / \mathrm{ml}$ & $75 \mu \mathrm{g} / \mathrm{ml}$ & $90 \mu \mathrm{g} / \mathrm{ml}$ \\
Peak Area* & 132603.4533 & 166423.573 & 197533.432 \\
\%RSD & 0.1619 & 0.9777 & 0.4213 \\
Mean\% recovery & 99.82 & 100.23 & 99.14 \\
\hline
\end{tabular}

*Mean of three trials.

\section{Limit of Detection (LOD) and Limit of quantification (LOQ)}

The limit of detection was found to be $0.088 \mathrm{ng} / \mathrm{ml}$ and limit of quantification was found to be $0.266 \mathrm{ng} / \mathrm{ml}$ for AST and similarly for ASP is $1.31 \mathrm{ng} / \mathrm{ml}$ and $3.98 \mathrm{ng} / \mathrm{ml}$ respectively. The results are shown in table 2. 


\section{Robustness}

Robustness was checked by making a slight deliberate change in the experimental procedure by slight change in the temperature, flow rate and $\mathrm{pH}$ and no significant change in area and retention time was found in all the parameters and all the values were found to be with in $2 \%$ relative standard deviation. The results of robustness are given in the table 5, 6, 7 .

Table 5. Robustness for flow rate studies (temperature).

\begin{tabular}{lll}
\hline Temperature $\left({ }^{\circ} \mathrm{C}\right)$ & Area (AST) & Area (ASP) \\
\hline 25 & 111802.563 & 163878.422 \\
30 & 112293.391 & 165872.156 \\
35 & 114609.32 & 169543.109 \\
Mean & 112901.758 & 166431.229 \\
\%RSD & 1.327 & 1.726 \\
\hline
\end{tabular}

Table 6. Robustness for $\mathrm{pH}$ studies.

\begin{tabular}{lll}
\hline $\mathbf{p H}$ & Area (AST) & Area (ASP) \\
\hline 4.4 & 116011.297 & 168410.359 \\
4.5 & 112293.391 & 165872.156 \\
4.6 & 113067.297 & 162874.891 \\
Mean & 113790.6617 & 165719.1353 \\
\%RSD & 1.723 & 1.672 \\
\hline
\end{tabular}

Table 7. Robustness for Flow rate Studies.

\begin{tabular}{lll}
\hline Flow rate $(\mathbf{m l})$ & Area $($ AST) & Area (ASP) \\
\hline 0.798 & 114018.961 & 165255.6 \\
0.8 & 112293.391 & 165872.2 \\
0.802 & 112194.805 & 161132.7 \\
Mean & 112835.719 & 164086.8 \\
\%RSD & 0.909 & 1.57 \\
\hline
\end{tabular}

\section{Analysis of the marketed products}

The proposed method was applied successfully to determine the content of AST and ASP in pharmaceutical product. The results are expressed in terms of percentage in Table 8 .

Table 8. Analysis of tablet formulation.

\begin{tabular}{cccc}
\hline Sl.No. & Parameters & AST & ASP \\
\hline 1 & Label claim(mg/tab) & $10 \mathrm{mg}$ & $75 \mathrm{mg}$ \\
2 & Drug content \% & $99.23 \pm 0.3373$ & $100.23 \pm 0.9805$ \\
3 & $\%$ RSD & 0.3399 & 0.9783 \\
\hline
\end{tabular}

\section{Conclusion}

The proposed HPLC method is simple and the total run time for the two components is less than 9 min. The quantitation of each component was not affected by any of the possible interfering substances included during tablet manufacturing. The method is accurate and precise as indicated from the recovery study. It can be concluded that the proposed HPLC method has great promise for the simultaneous determination of two components in pharmaceutical formulations. 


\section{Acknowledgement}

The authors are thankful to Gokula Education Foundation for providing necessary facilities to carry out the research work and Biocon Limited Bangalore, for providing a gift sample of standard atorvastatin calcium.

\section{References}

1. Indian Pharmacopoeia Health ministry of India, 2010, Vol.II 849

2. Indian Pharmacopoeia Health ministry of India, 2010, Vol.II 1776, British Pharmacopoeia, the stationery office on behalf of the medicines and health care products regulatory agency, 2007,Vol.II 1466-1467.

3. Erk.N Analytical Letters 2003, 36 (12),2699-2711

4. Jemal M, Ouyang Z, Chen B C, Teitz D Rapid Commun Mass Spectrom, 1999, 13, 1003-1015

5. Erturk S, Sevinc A E, Ersoy L, Ficicioglu S. J Pharm Biomed Anal 2003,33, 1017-1023

1. 6. Puratchikody A, Valarmathy R, Shiju P J Rukumani K. Pharm Rev 2003, 1, 79-80

6. Sankar D G, Raju M S M, Sumanth K, Latha P V M. Asian J Chem 2005,17, 2571-2574

7. Stanisz B, Kania L Validation of HPLC method for determination of atorvastatin in tablets and for monitoring in solid phase. Acta Pol Pharm 2006, 63, 471-476

8. Bahrami G, Mohammadi B, Mirzaeei S, Kiani A. J Chromatogr B: Analyt Technol Biomed Life Sci 2005, 826, 41-45.

9. Hermann M, Christensen H, Reubsaet J L Anal Bioanal Chem 2005, 382, 1242-1249

10. Petkovska R, Comett C, Dimitrovska A, Analytical letters, April 2008, 41(6),992-1009.

11. Guiphen E, Sisk G D, Scully N M, Glennon J D Electrophoresis 2006, 27,2338-47

12. Dhaneshwar S R, Yadav S, Mhaske A, Kadam S Indian J Pharm Sci 2005,67, 182-186

13. J.Anwar and T.A.Awan, J Chem Soc Pak 1990, 12(1)

14. Szostak R, Mazurek S (2002).Analyst, 2002, 127, 144-148.

15. Ramos martos N, Aguirr-gomez F, Molina Diaz A, Capitan Vallvey LF J. AOAC int, May-Jun 2001, 84(3), 676-683

16. ICH, Guidance on Analytical Method Validation, in: Proceedings of International Convention on Quality for the Pharmaceutical Industry, Toronto, Canada, September 2002. 


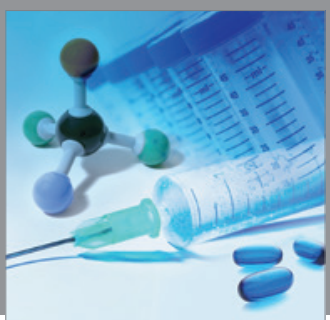

International Journal of

Medicinal Chemistry

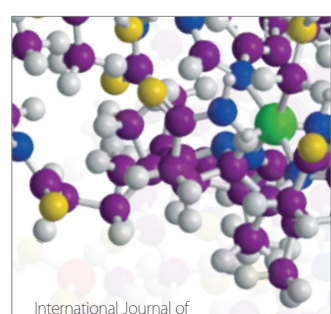

Carbohydrate Chemistry

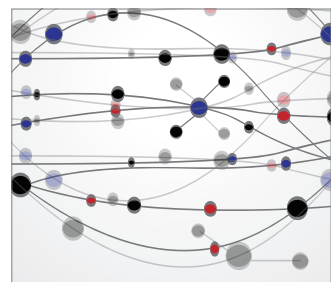

The Scientific World Journal
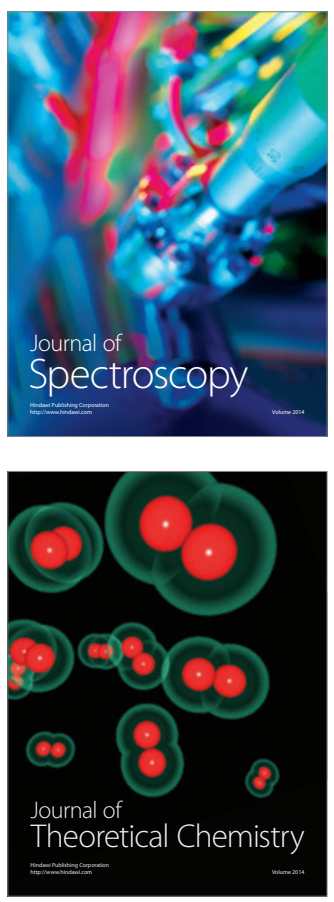
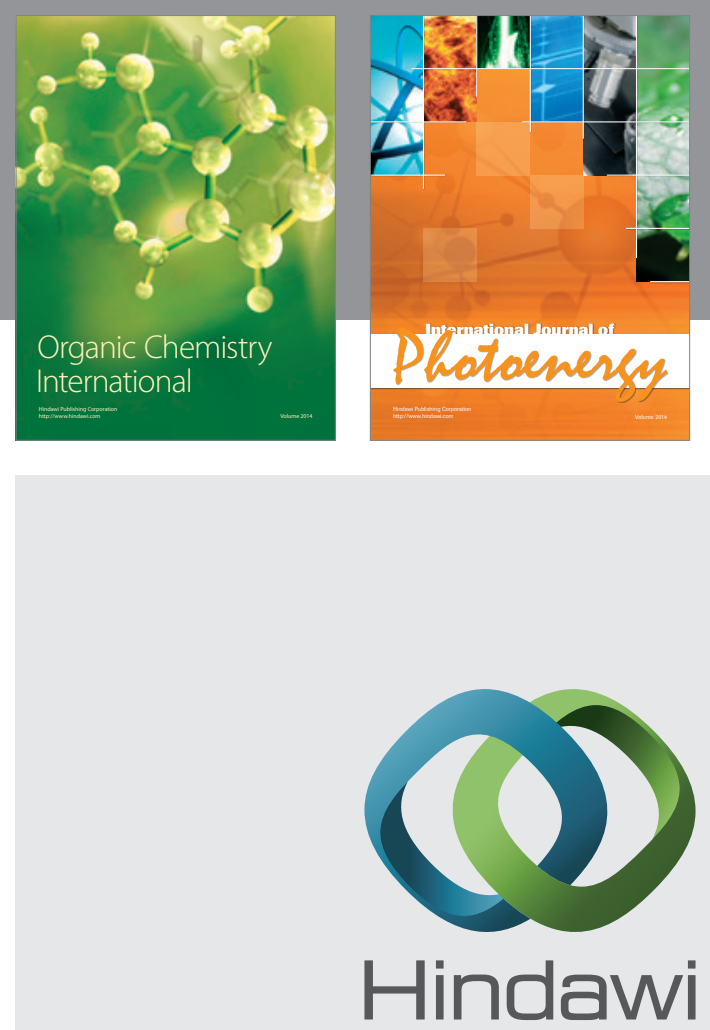

Submit your manuscripts at

http://www.hindawi.com
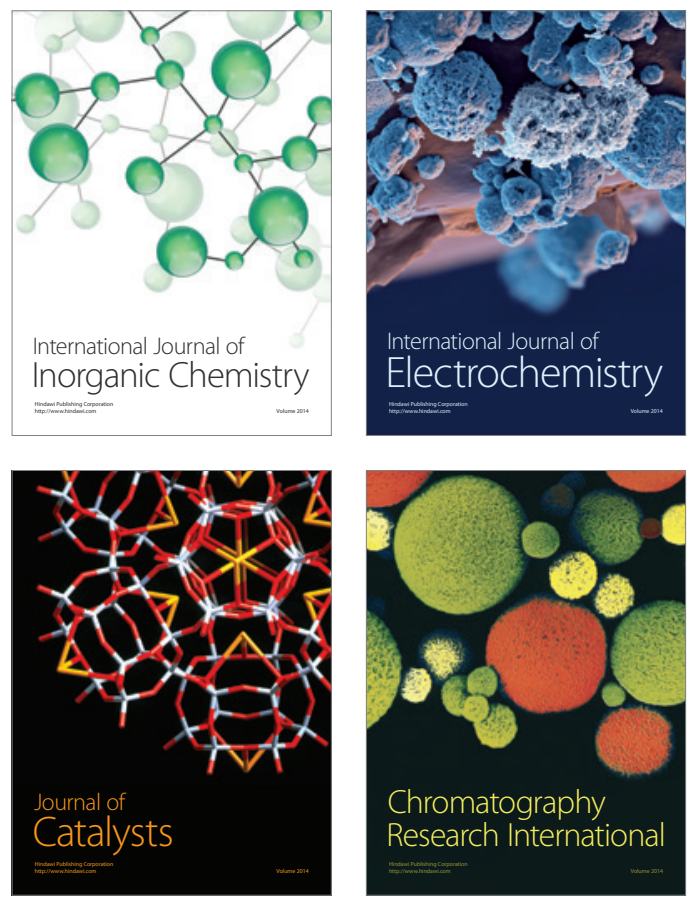
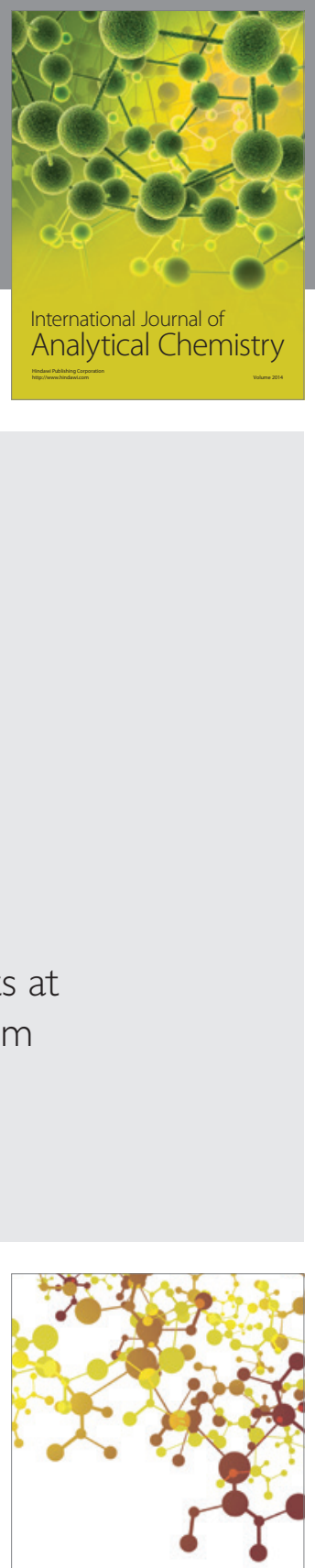

Journal of

Applied Chemistry
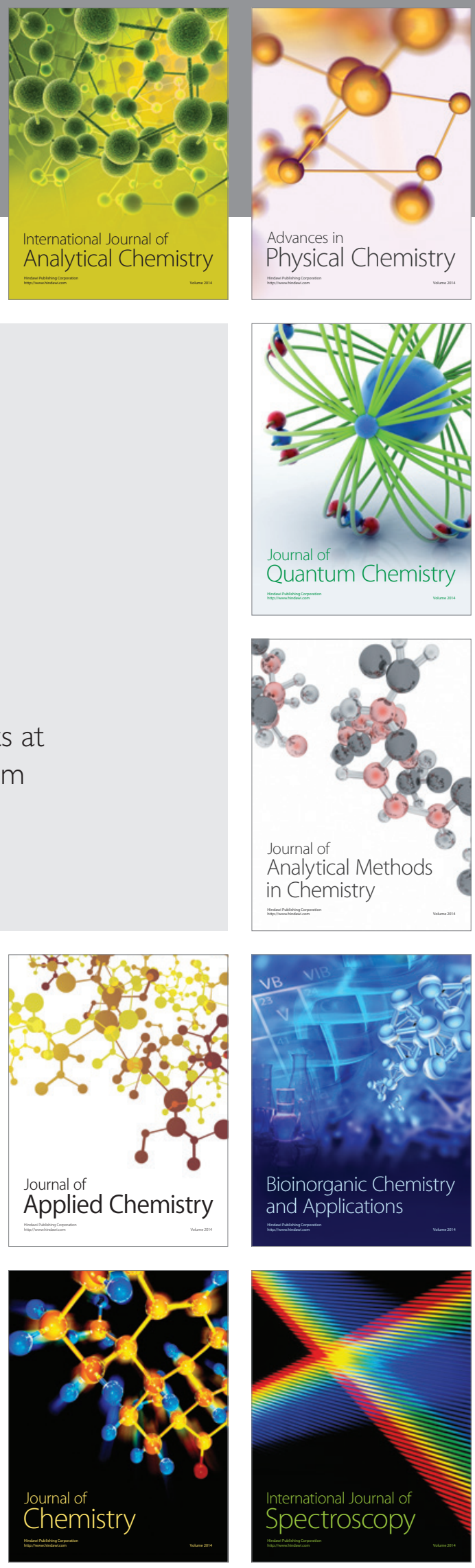